\title{
HYDRODYNAMIC STUDIES IN SIEVE PLATE WITH RELATIVELY SHORT VERTICAL PIPES
}

\author{
TERUO TAKAHASHI, TOSHIRO MIYAHARA, TOSHIO SATO \\ AND YASUYOSHI SANADA \\ Department of Industrial Chemistry, Okayama University, Okayama 700
}

\begin{abstract}
Key Words: Fluid Mechanics, Distillation, Absorption, Pressure Drop, Liquid Holdup, Annular Flow, Two Phase Flow, High Gas Velocity, Sieve Plate, Plate Column

Pressure drop and liquid holdup for a device with a relatively short vertical pipe operating at high gas velocity were experimentally studied.

An analysis of pressure drop and liquid holdup is carried out, using the principle of minimum entropy production proposed by S. M. Zivi, which includes the friction factor for annular two-phase flow and the correction factor for predicting total pressure drop. Correlations for these parameters are obtained empirically.
\end{abstract}

\section{Introduction}

Recently, the chemical industry has felt the need of high-capacity gas-liquid contacting devices because of increases in production, the cleaning of waste gases or the importance of saving energy. However, operations at high gas velocities in the usual gas-liquid contacting devices such as sieve plate columns or packed columns are limited by flooding of the column.

The authors ${ }^{9,10,12)}$ have investigated the flooding velocity of various gas-liquid contactors of column type such as packed columns, wetted-wall columns and plate columns with and without downcomers, and found that operations at high gas velocities require large fractional void space, large column diameter and large free area.

For the reason mentioned above, a new tray-type equipment with short vertical pipes has been proposed, in which co-current gas-liquid contacting by entrained liquid film takes place. The equipment can be used at much higher gas velocities than the flooding velocities of the usual gas-liquid contacting equipment.

Angelino et al. ${ }^{2)}$ investigated a device with pipes with an extremely small hole diameter of $0.042 \mathrm{~cm}$. Nikolaev et $a l^{5}{ }^{5}$ derived equations to explain the effect of the number of sectioning stages and liquid circulation rate on the efficiency of the contact stage. Though numerous investigations relevant to characteristics of two-phase flow in a long vertical pipe of small diameter have been carried out, little attention has been focused on the flow in a relatively short vertical pipe of large diameter.

Received March 28, 1986. Correspondence concerning this article should be addressed to T. Miyahara. Y. Sanada is now with Harima Chem. Inc
In the present work, pressure drop and liquid holdup of the device with a short single pipe of large diameter were experimentally studied.

A theoretical approach, using the principle of minimum energy dissipation proposed by Zizi, ${ }^{14 !}$ was also made to predict pressure drop and liquid holdup of the equipment. It showed good agreement with the measurements.

\section{Theoretical Development}

For vertical co-current flow, there appear various regimes of two-phase flow: bubble, slug, churn and annular flow depending on the rate of gas and liquid. ${ }^{4)}$ We consider here annular two-phase flow without liquid entrainment as shown in Fig. 1.

Total pressure drop for this device is assumed to be the sum of dry pressure drop, pressure drop due to liquid holdup and acceleration of liquid from horizontal to vertical direction.

$$
\Delta P_{t}=\Delta P_{1}+\Delta P_{2}+\zeta\left(\Delta P_{3}+\Delta P_{4}+\Delta P_{5}\right)
$$

where $\Delta P_{1}$ and $\Delta P_{2}$ are pressure drop due to the contraction and expansion of gas, respectively, and can be expressed as

$$
\begin{gathered}
\Delta P_{1}=C_{c} U_{g}^{2} \rho_{g} / 2 \\
\Delta P_{2}=\left(1-A_{p} / A_{c}\right)^{2} U_{g}^{2} \rho_{g} / 2
\end{gathered}
$$

where $C_{c}$ is the contraction coefficient, the value of which is assumed to be 0.5 because of the small value of $A_{p} / A_{c}{ }^{6}{ }^{6}$ Friction energy loss of annular two-phase flow $\Delta P_{3}$, pressure drop due to liquid holdup $\Delta P_{4}$ and pressure drop necessary to accelerate liquid $\Delta P_{5}$ are estimated from the following equation:

$$
\begin{aligned}
& \Delta P_{3}=4 f_{T P}\left(Z_{p} / D\right) u_{l}^{2} \rho_{l} / 2 \\
& \Delta P_{4}=\varphi Z_{p} \rho_{l} g
\end{aligned}
$$




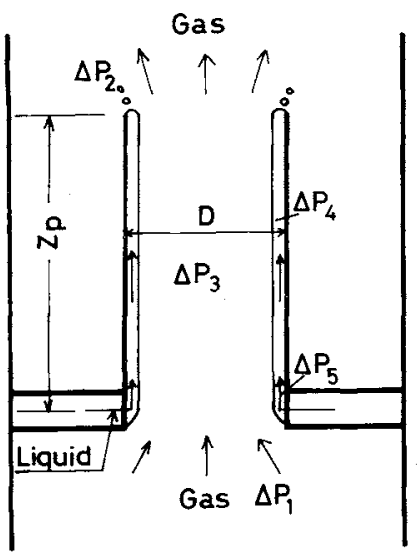

Fig. 1. A model for annular two-phase flow in a relatively short pipe.

$$
\Delta P_{5}=L^{2} /\left(\varphi \rho_{l}\right)
$$

The correction factor indicating the deviation from annular two-phase flow without liquid entrainment, $\zeta$, can be determined experimentally. Therefore, we can estimate total pressure drop $\Delta P_{t}$ by Eq. (1), if friction factor $f_{T P}$, correction factor $\zeta$ and liquid holdup $\varphi$ are given.

We assume the following conditions:

1) Pressure is uniform in the radial direction in the pipe.

2) The flow is at steady state.

The pressure drop of two-phase flow per unit length in the pipe is given by

$$
(\Delta P / Z)_{T P}=A P / Z-\left\{(1-\varphi) \rho_{g}+\varphi \rho_{l}\right\} g
$$

The friction factor for two-phase flow may be obtained as

$$
\begin{aligned}
f_{T P} & =(1 / 2)(\Delta P / Z)_{T P} D /\left(u_{l}^{2} \rho_{l}\right) \\
& =(1 / 2)(\Delta P / Z)_{T P} D \varphi^{2} \rho_{l} / L^{2}
\end{aligned}
$$

Usually, the friction factor has been correlated in the following manner, that is, in terms of the Reynolds number.

$$
f_{T P}=a R e^{b}=a\left(\frac{D U_{l} \rho_{l}}{\mu_{l}}\right)^{b}
$$

The kinetic energy flux is given by the following equation.

$$
E=(1 / 2) G u_{g}^{2}+(1 / 2) L u_{l}^{2}
$$

The dissipation energy flux at the wall is

$$
W=2 \rho_{l} f_{T P} u_{l}^{3} Z / D
$$

We will try to apply the principle of minimum energy dissipation proposed by $\mathrm{Zivi}^{14)}$ for the determination of liquid holdup to give

$$
\begin{aligned}
\frac{d}{d \varphi}(E+W)= & u_{g} G \frac{d u_{g}}{d \varphi}+u_{l} L \frac{d u_{l}}{d \varphi} \\
& +\frac{6 a Z \rho_{l}}{D}\left(\frac{D L}{\mu_{l}}\right)^{b} u_{l}^{2} \frac{d u_{l}}{d \varphi}=0
\end{aligned}
$$

where $u_{g}=G /\left\{(1-\varphi) \rho_{g}\right\}$ and $u_{l}=L /\left(\rho_{l} \varphi\right)$, which reduces to

$$
\frac{G^{3}}{\rho_{g}^{2}(1-\varphi)^{3}}-\frac{L^{3}}{\rho_{l}^{3} \varphi^{3}}-\frac{6 a Z D^{b-1} L^{b+3}}{\mu_{l}^{b} \rho_{l}^{2} \varphi^{4}}=0
$$

Eq. (13) allows the prediction of liquid holdup in annular two-phase flow.

\section{Experimental Apparatus and Procedure}

The experimental apparatus is schematically represented in Fig. 2(A). An rectangular acrylic resin column $(0.2 \times 0.2 \times 1.975 \mathrm{~m})$ having a single pipe inside to be tested was used. The temperature of liquid was controlled by using a cooler and a heater. Total pressure drop $\Delta P_{t}$ was obtained by using a manometer and pressure taps fitted normal to the column wall as shown in Fig. 2(A). Pressure taps for measuring pressure drop for two-phase flow were at a distance of $0.2 \mathrm{~m}$ above the liquid entrance and $0.1 \mathrm{~m}$ below the top of the pipe as also shown in Fig. 2(A), since under the present experimental conditions there was no appreciable variation in the longitudinal direction along the pipe.

Liquid holdup was measured by means of a shutter technique as shown in Fig. 2(B); after steady state was reached, supply of gas and liquid was stopped by the shutter to measure the amount of liquid in a pipe. Details of the shutter and the gas-liquid mixing section are shown in Figs. 3(A) and (B), respectively. The range of pipe length and diameter were 0.15 $0.9 \mathrm{~m}$ and $0.0294-0.0467 \mathrm{~m}$, respectively. Superficial gas velocity based on empty pipe was varied from 1 to $80 \mathrm{~m} / \mathrm{s}$, while the mass flow rate of liquid per unit cross-section area was $10-350 \mathrm{~kg} / \mathrm{m}^{2} \mathrm{~s}$. Details of the physical properties of liquids employed are listed in Table 1.

\section{Results and Discussion}

\subsection{Flow pattern}

Figure 4 shows an example of photographs of flow patterns in a pipe. Figure 4(a) is for $U_{g}=0$ and $L=0$. At low gas flow rate as shown in (b), liquid moves upward with vertical oscillation, in which liquid holdup is relatively high. Increase in gas rate causes the wavy motion in (c). Figure 4(d) shows perfect annular two-phase flow; relatively uniform liquid film is formed. Further increase in gas flow illustrated in (e) produces ripples on the surface of the film to become annular mist flow. Liquid holdup decreases with increasing gas velocity, that is, from (b) to (c). 


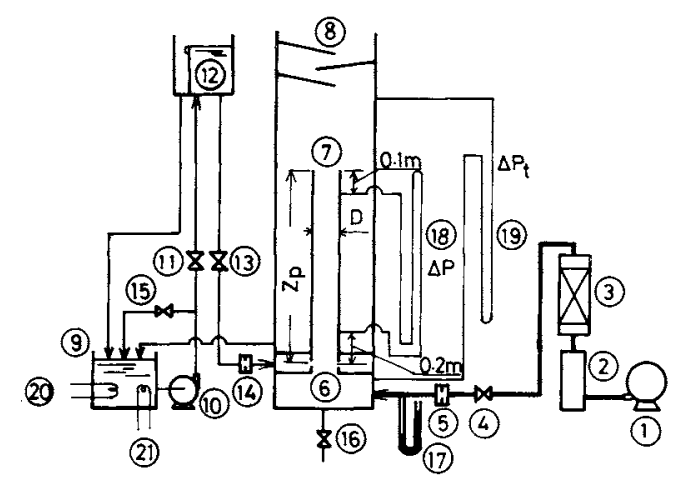

(A)

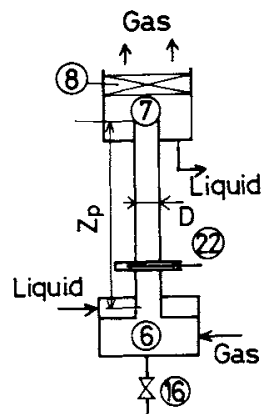

(B)

Fig. 2. Schematic diagram of experimental apparatus. 1, blower; 2 , buffer tank; 3, packed tower; 4, valve; 5 , orifice flow meter; 6 , mixing section; 7 , test section; 8 , demister; 9 , reservoir; 10 , pump; 11, valve; 12 , head tank; 13 , valve; 14 , orifice flow meter; 15,16 , valve; 17 , safety device; 18,19 , manometer; 20 , cooler; 21 , heater; 22 , shutter.

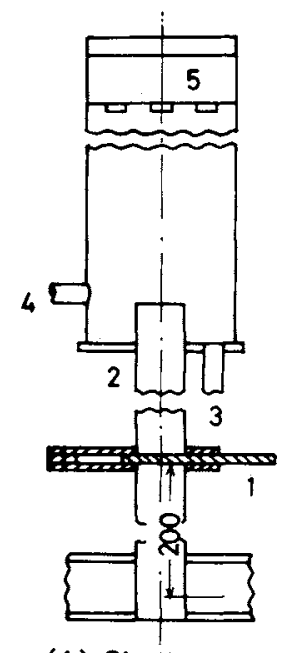

(A) Shutter
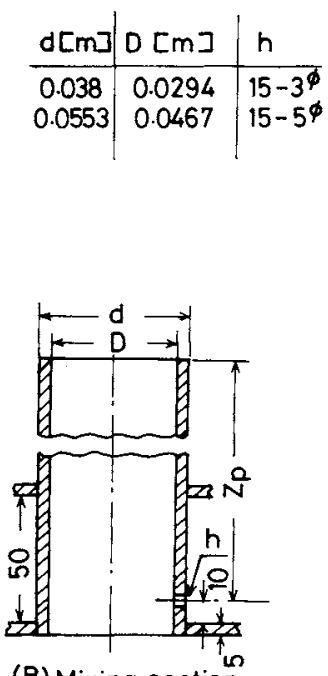

(B) Mixing section
Fig. 3. Details of shutter and mixing section. 1, shutter; 2, test section; 3,4 , pipe; 5 , demister.

Table 1. Physical properties of liquids

\begin{tabular}{cccc}
\hline Liquid & $\begin{array}{c}\text { Density } \\
\rho_{l}\left[\mathrm{~kg} / \mathrm{m}^{3}\right]\end{array}$ & $\begin{array}{c}\text { Viscosity } \\
\mu_{l}[\mathrm{~Pa} \cdot \mathrm{s}]\end{array}$ & $\begin{array}{c}\text { Surface tension } \\
\sigma[\mathrm{N} / \mathrm{m}]\end{array}$ \\
\hline $\begin{array}{c}\text { Water } \\
\begin{array}{c}\text { Millet jelly } \\
\text { aq. soln. I } \\
\text { Millet jelly } \\
\text { aq. soln. II }\end{array}\end{array}$ & 1000 & 0.001 & 0.0072 \\
\hline
\end{tabular}

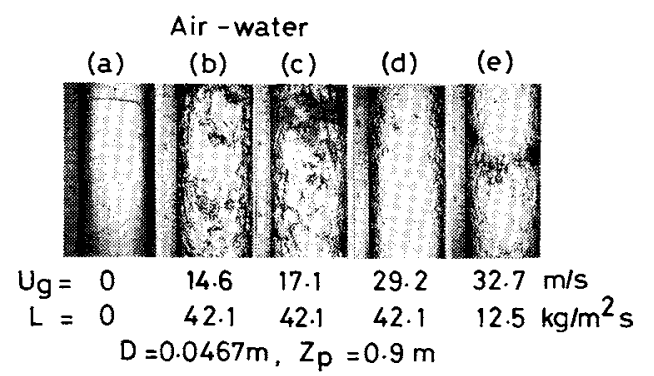

Fig. 4. Flow patterns.

\subsection{Friction factor for two-phase flow}

Figure 5 shows the pressure drop for two-phase flow in water. As can be seen from the figure, pressure drop takes a minimum with critical gas velocity below which annular flow disappears as described by Calvert et al. ${ }^{3)}$; it is the lower limit of annular twophase flow. The increase in liquid viscosity indicates a slight increase in pressure drop, which is not shown here.

Figure 6 shows the correlation of friction factor. From this figure, the friction factor shows a change of behavior at a Reynolds number $R e_{l}$ of about 2000 though there was scattering. The data are well correlated by the following equations.

$$
\begin{array}{cc}
f_{T P}=3.5 R e_{l}^{-3 / 4} & R e_{l}<2000 \\
f_{T P}=0.0791 R e_{l}^{-1 / 4} & R e_{l}>2000
\end{array}
$$

In the figure, results of Anderson et al., ${ }^{1)}$ Sasaki $^{7)}$ and Shiba et $a l .^{8)}$ for long pipe are also shown. The exponent of the Reynolds number for annular twophase flow is less than that for single-phase flow, being equal to -1 . This result agrees with that of Sasaki ${ }^{7)}$ for a long pipe, while Eq. (15) over a range of $R e_{l}>2000$, corresponding to the turbulent flow of single-phase flow, is identical to the Blasius equation.

\subsection{Liquid holdup}

Experimental measurements of liquid holdup are shown in Fig. 7. Liquid holdup decreases with increasing gas velocity, and increases with liquid velocity. A sharp decrease in liquid holdup with increasing gas velocity corresponds to the wave region, and liquid holdup has the trend of gradual decrease with increasing gas velocity. At still higher gas velocity, liquid holdup is nearly constant. Another result showed that the liquid viscosity caused high liquid holdup.

Solid lines in Fig. 7 show the values by Eq. (13) together with Eqs. (14) and (15). The dashed-dot lines and dashed lines in Fig. 7 are the results proposed by 


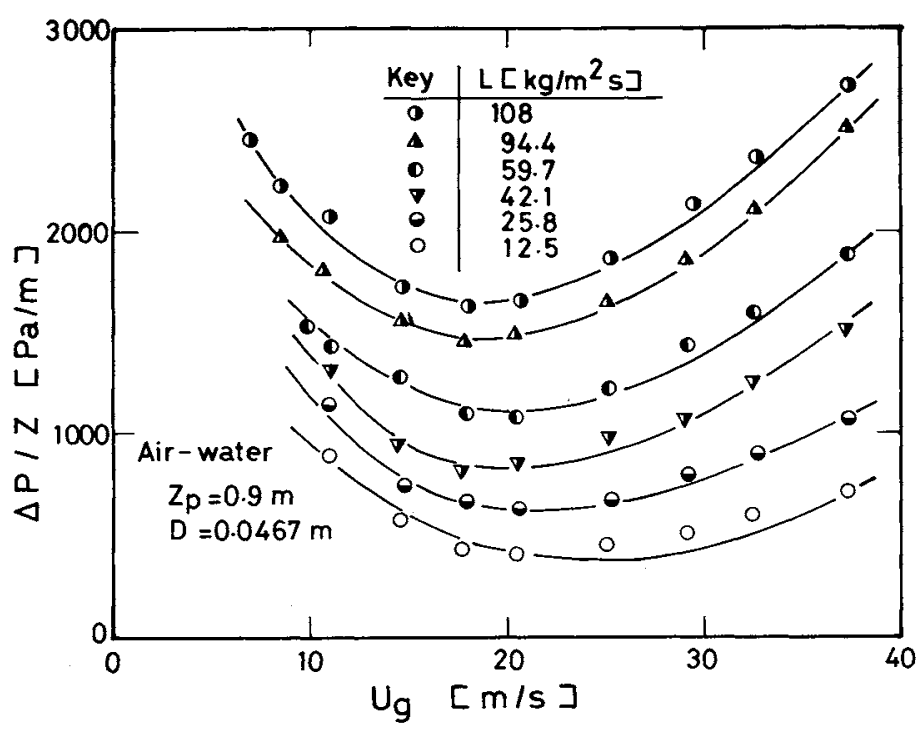

Fig. 5. Pressure drop for annular two-phase flow.

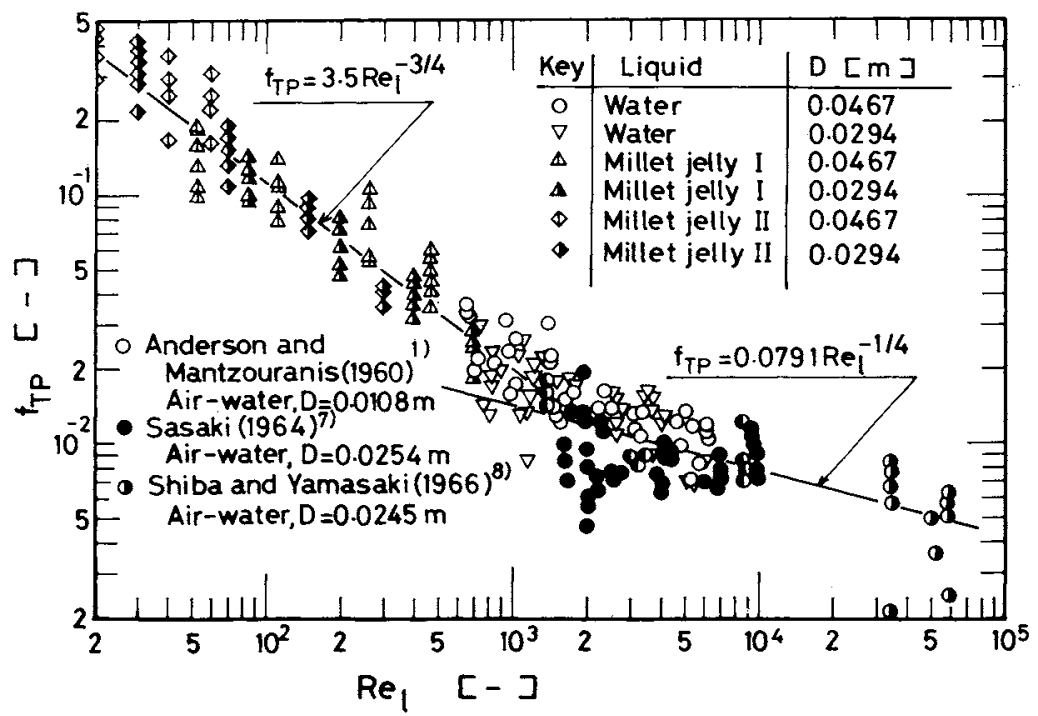

Fig. 6. Correlation of friction factor.

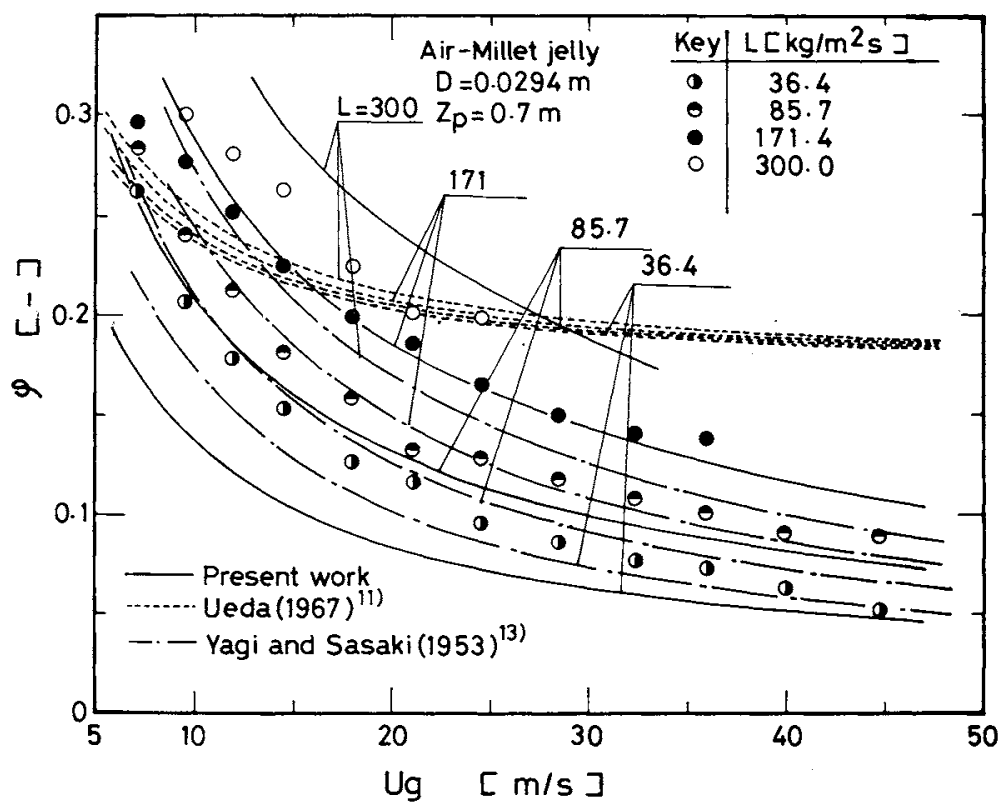

Fig. 7. Liquid holdup for annular two-phase flow. 
Yagi et al. $^{13)}$ and Ueda ${ }^{11)}$ respectively for a long pipe of small diameter, as expressed by the following equations.

$$
\begin{aligned}
& \varphi /(1-\varphi)=700\left(\frac{U_{l}}{U_{g}}\right)^{0.88} L^{-0.6} \mu_{l}^{0.2} \\
& 1 /(1-\varphi)=1.20\left(1+\frac{U_{l}}{U_{g}}\right)+\frac{U_{b}}{U_{g}}
\end{aligned}
$$

where

$$
U_{b}=2.4 \times 10^{-8} \frac{\left(\rho_{l}-\rho_{g}\right) g}{\mu_{l}}-D^{2}\left(\frac{\mu_{l}}{\mu_{g}}\right)^{5 / 3}
$$

Each equation shows appreciable difference between predicted values and the measurements, especially in the case of higher liquid load and lower gas velocity. For lower liquid load and higher gas velocity, which would depend on the annular flow, however, Eq. (13) shows relatively good agreement. From experiments, we obtained further knowledge about liquid holdup, namely that liquid holdup has a tendency to become higher with pipe length but not with pipe diameter.

\subsection{Correction factor}

It is necessary to obtain in advance the correction factor, $\zeta$, in Eq. (1), values of which were estimated from observed pressure drops by use of Eq. (1) together with Eqs. (2), (3), (4), (5), (6), (13), (14) and (15). Figure 8 shows the correlation for $\zeta$. The solid line in the figure represents the following equation.

$$
\zeta=0.188\left(\operatorname{Re}_{g} \cdot R e_{l}\right)^{1 / 10}
$$

\subsection{Total pressure drop}

Figure 9 shows data of total pressure drop together with dry pressure drop. As illustrated in this graph, there is a distinct pattern: a maximum and a minimum in total pressure drop with increasing gas velocity. The maximum corresponds to the weeping point, while the minimum corresponds to the annular point. The increase in liquid load leads to an increase in total pressure drop. Calculated curves fit the measurements approximately over the range of gas velocity greater than that of the annular point, that is, the minimum in pressure drop.

\section{Conclusions}

In an attempt to obtain hydrodynamic characteristics of the new tray-type contacting equipment with short vertical pipes, pressure drop and liquid holdup for co-current annular vertical flow in a single pipe of relatively short length were studied theoretically and experimentally. The following results were noted:

1) The friction factor for gas-liquid annular twophase flow in a relatively short vertical pipe can be correlated with the Reynolds number based on the liquid velocity in the annular flow region.

2) A theoretical approach to liquid holdup was

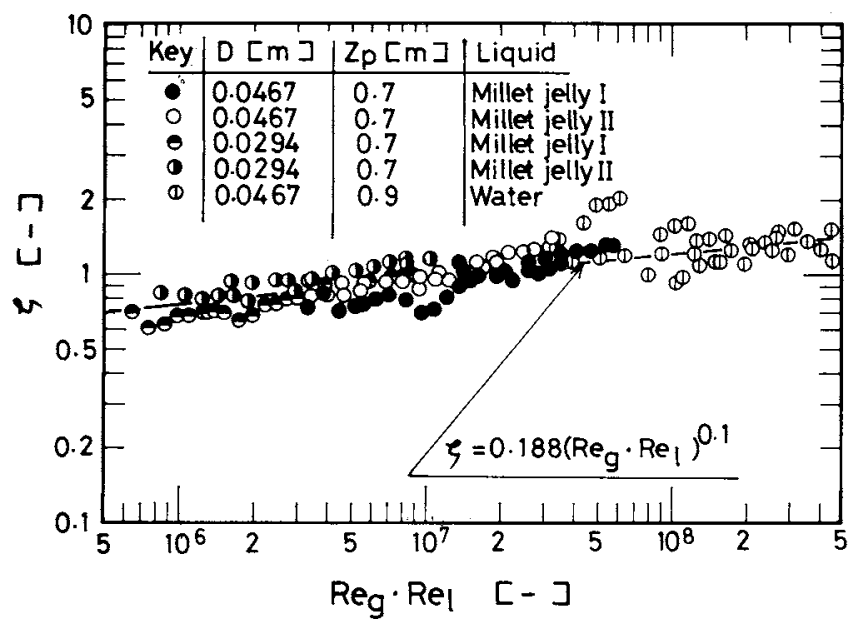

Fig. 8. Correlation of correction factor.

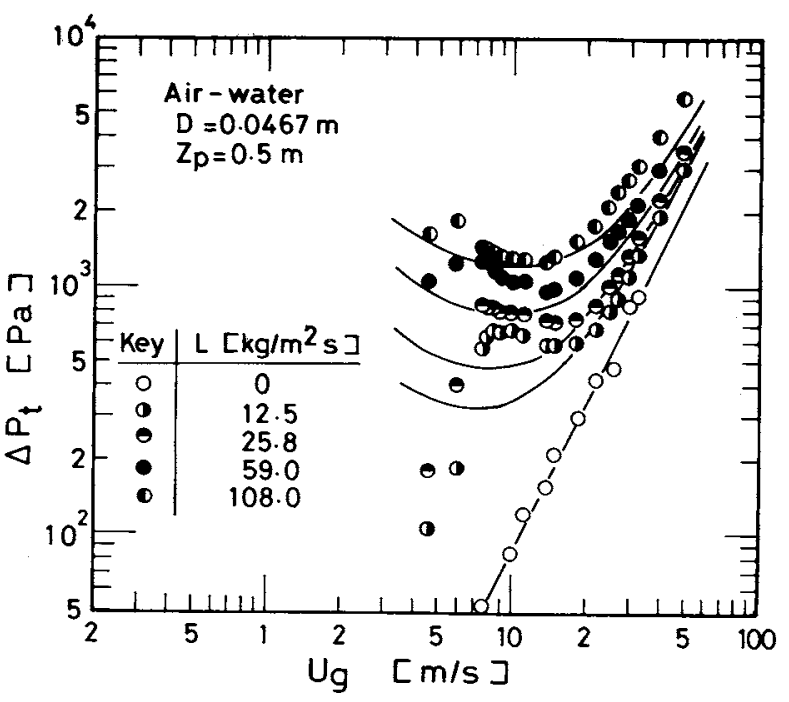

Fig. 9. Total pressure drop.

taken and showed good agreement with the measurements in the range of lower liquid loads and higher gas velocities, that is, in the annular flow region.

3) The total pressure drop could be estimated by Eq. (1) using correlations of friction factor, correction factor and liquid holdup.

\section{Nomenclature}

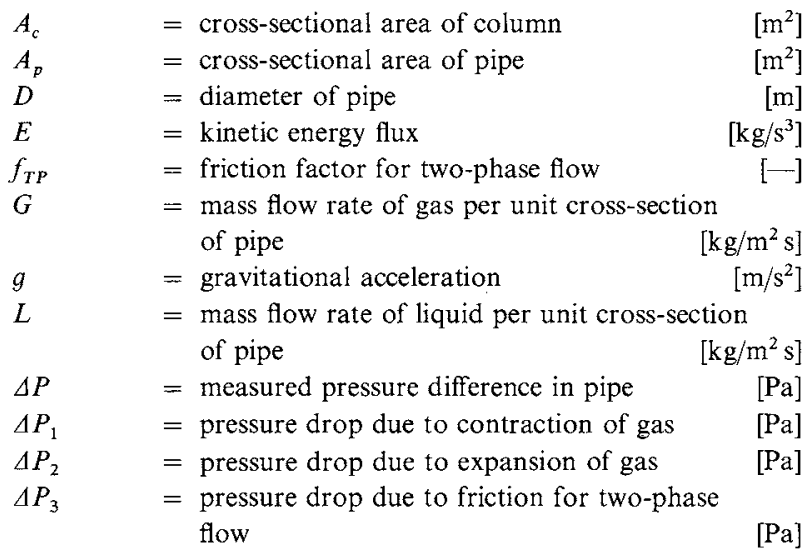




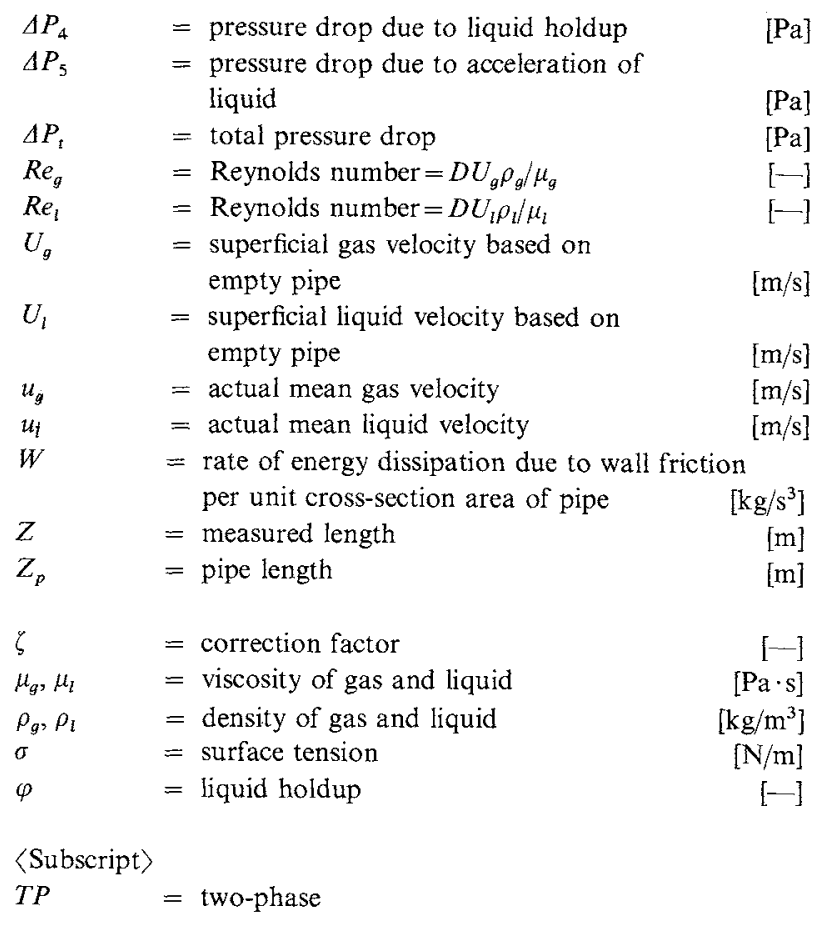

1) Anderson, G. H. and B. G. Mantzouranis: Chem. Eng. Sci., 12, $109(1960)$.

2) Angelino, G. C., B. Brigoli and M. Silvestri: Energia Nuclear, 10, 85 (1963).

3) Calvert, S. and B. Williams: AIChE J., 1, 78 (1955).

4) Hewitt, G. F. and N. S. Hall-Taylor: "Annular Two-phase Flow," Pergamon Press (1970).

5) Nikolaev, N. A. and V. A. Bulkin: Intern. Chem. Eng., 12, 438 (1972).

6) Pery, G. H., C. H. Chilton and S. P. Kirkpatrik: "Chemical Engineer's Handbook," 4th ed., pp. 5-30 (1963).

7) Sasaki, T.: Kagaku Kōgaku, 28, 110 (1964).

8) Shiba, M. and Y. Yamazaki: Trans. JSME, 32, 1231 (1966).

9) Takahashi, T., Y. Akagi and K. Fujita: J. Chem. Eng. Japan, 6, 97 (1973).

10) Takahashi, T., Y. Akagi, K. Fujita and T. Kishimoto: $J$. Chem. Eng. Japan, 7, 223 (1974).

11) Ueda, T.: Trans. JSME, 33, 611 (1967).

12) Wallis, G. B., T. Takahashi and Y. Akagi: J. Chem. Eng. Japan, 8, 341 (1975).

13) Yagi, S. and T. Sașaki: Kagaku Kōgaku, 17, 216 (1953).

14) Zivi, S. M.: Trans. ASME J. Heat Transfer, C-86, 247 (1964).

(Presented at the Hokuriku Meeting of the Society of Chemical Engineers, Japan, at Toyama, July 1974, July 1976.)

\title{
GAS SEPARATION BY MEANS OF A POROUS MEMBRANE WITH COCURRENT AND COUNTERCURRENT FLOWS
}

\author{
KENII HARAYA, YUJI SHINDO, TOSHIKATSU HAKUTA \\ AND HIROSHI YOSHITOME \\ Process Research and Development Division, National Chemical Laboratory for Industry, \\ Tsukuba 305
}

Key Words: Membrane Separation, Porous Membrane, Gas Separator, Cocurrent Flow, Countercurrent Flow, Present-deBethune's Equation

In the previous paper, ${ }^{11}$ the authors reported that the point efficiencies of a porous glass membrane for the separation of $\mathrm{H}_{2}-\mathrm{CO}$ mixture could be explained reasonably by a semiempirical method based on the permeation equation proposed by Present and deBethune. ${ }^{2)}$ It is preferable to employ their equation for prediction of the performance of separators made of porous membrane over a wide range of pressure. However, no application of their equation has been reported in the literature.

In this paper, a calculation method for gas separators made of porous membranes is developed using

Received December 6, 1985. Correspondence concerning this article should be addressed to K. Haraya.
Present and deBethune's formula as the basic permeation equation. It gives fairly good accordance with experimental data in cocurrent and countercurrent flow modes.

\section{Calculation Method}

Calculation equations for cocurrent and countercurrent flow separators are derived, based on the following assumptions.

1) Permeation of each component in a binary mixture obeys Present and deBethune's equation, in which the zero pressure limit of the permeability is given by the observed Knudsen permeability.

2) Pressure drop occurs only across the mem- 